\title{
(2) OPEN ACCESS \\ Associations between family presence and neonatal intubation outcomes: a report from the National Emergency Airway Registry for Neonates: NEAR4NEOS
}

\author{
Brianna K Brei (10 , ${ }^{1,2}$ Taylor Sawyer, $^{2}$ Rachel Umoren, ${ }^{2}$ Megan M Gray 다 , \\ Jeanne Krick, ${ }^{3}$ Elizabeth E Foglia (1) , ${ }^{4}$ Anne Ades, ${ }^{4}$ Kristen Glass, ${ }^{5}$ Jae H Kim, ${ }_{1}^{6,7}$ \\ Neetu Singh, ${ }^{8}$ Philipp Jung, ${ }^{9}$ Lindsay Johnston, ${ }^{10}$ Ahmed Moussa $\left({ }^{\circ},{ }^{11}\right.$ \\ Natalie Napolitano, ${ }^{12}$ James Barry, ${ }_{1}^{13}$ Jeanne Zenge, ${ }^{13}$ Binhuey Quek, ${ }_{1}^{14}$ \\ Stephen D DeMeo, ${ }^{15}$ Justine Shults, ${ }^{16}$ Jennifer Unrau, ${ }^{17}$ Vinay Nadkarni, 18,19 \\ Akira Nishisaki, ${ }^{18,19}$ On behalf of the National Emergency Airway Registry for Neonates \\ (NEAR4NEOS) investigators
}

\begin{abstract}
- Additional material is published online only. To view please visit the journal online (http://dx.doi.org/10.1136/ fetalneonatal-2020-319709).

For numbered affiliations see end of article.
\end{abstract}

\section{Correspondence to} Dr Brianna K Brei, Pediatrics, Division of Neonatology, University of Nebraska Medical Center, Omaha, NE 68198, USA; brianna.brei@unmc.edu

Received 18 May 2020 Revised 21 November 2020 Accepted 2 December 2020 Published Online First 21 January 2021

\section{Check for updates}

(C) Author(s) (or their employer(s)) 2021. Re-use permitted under CC BY-NC. No commercial re-use. See rights and permissions. Published by BMJ.

To cite: Brei BK, Sawyer T, Umoren $\mathrm{R}$, et al. Arch Dis Child Fetal Neonatal Ed 2021;106:F392-F397.

\begin{abstract}
Objective Describe the current practice of family presence during neonatal tracheal intubations (TIS) across neonatal intensive care units (NICUs) and examine the association with outcomes.

Design Retrospective analysis of Tls performed in NICUs participating in the National Emergency Airway Registry for Neonates (NEAR4NEOS).

Setting Thirteen academic NICUs.

Patients Infants undergoing TI between October 2014

\section{What is already known on this topic?}

The American Academy of Pediatrics advocates for family-centred care during procedures.

- Family-centred care in the neonatal intensive care unit (NICU) would advocate for family presence during intubation.

- In the NICU, little is known about the practice of family presence and the association with intubation outcomes.
\end{abstract} and December 2017.

Main outcome measures Association of family presence with $\mathrm{TI}$ processes and outcomes including first attempt success (primary outcome), success within two attempts, adverse TI-associated events (TIAEs) and severe oxygen desaturation $\geq 20 \%$ from baseline. Results of the $2570 \mathrm{TIs}, 242(9.4 \%)$ had family presence, which varied by site (median $3.6 \%$, range $0 \%-33 \% ; p<0.01)$. Family member was more often present for older infants and those with chronic respiratory failure. Fewer TIs were performed by residents when family was present (FP 10\% vs no FP 18\%, $p=0.041$ ). Among TIs with family presence versus without family presence, the first attempt success rate was $55 \%$ vs $49 \%(p=0.062)$, success within two attempts was $74 \%$ vs $66 \%(p=0.014)$, adverse TIAEs were $18 \%$ vs $20 \%(p=0.62)$ and severe oxygen desaturation was $49 \%$ vs $52 \%,(p=0.40)$. In multivariate analyses, there was no independent association between family presence and intubation success, adverse TIAEs or severe oxygen desaturation. Conclusion Family are present in less than 10\% of TIs, with variation across NICUs. Even after controlling for important patient, provider and site factors, there were no significant associations between family presence and intubation success, adverse TIAEs or severe oxygen desaturation.

\section{INTRODUCTION}

Patient and family-centred care (FCC) is widely accepted as the standard of care at paediatric healthcare facilities. ${ }^{1}$ In the neonatal intensive care unit (NICU), FCC is exemplified in unrestricted

\section{What this study adds?}

- Family presence during neonatal intubation varies widely across NICUs, with an average of $<10 \%$ of all intubations.

- Family presence does not influence the success of intubation and is not associated with adverse events during intubation.

- Family presence during neonatal intubation can be considered as part of a family centred care model.

family presence at the bedside, kangaroo care, breast feeding, participating in infant care times and bedside rounds. ${ }^{2}{ }^{3}$ FCC has many positive benefits including decreased length of hospital stay, improved well-being of preterm infants, increased parent-infant attachment and bonding, improved family satisfaction and decreased parental anxiety. ${ }^{24-7}$

The American Academy of Pediatrics policy statement on FCC supports offering family members to be present with their child during procedures. ${ }^{1}$ Similarly, healthcare providers should offer family members the opportunity to be present during the resuscitation of their child. ${ }^{8}$ Despite these recommendations, clinicians have raised concerns about the impact of family presence on procedural outcomes. ${ }^{9}$ Commonly expressed concerns include possible disruption of the procedure, increased team 
stress, ${ }^{10}$ performance anxiety of the proceduralist, ${ }^{11}$ increased anxiety of family members, potential traumatic experience for the families and risk of legal repercussions. ${ }^{12}{ }^{13}$ However, many family members still wish to be present during procedures, and their presence likely positively impacts both patients and other family members. ${ }^{9}$

Previous work on family presence during tracheal intubations (TIs) in the paediatric intensive care unit (PICU) showed no association with adverse effects. ${ }^{14}$ In the NICU, however, little is known about the impact of family presence during invasive procedures. The primary aims of this study were to describe the current practice of family presence during neonatal TI and examine associations of family presence during neonatal TI with intubation success and adverse TI-associated events (TIAEs) or severe oxygen desaturation. We hypothesised that family presence is not associated with these adverse intubation outcomes.

\section{METHODS}

Study design

This was a retrospective cohort study using prospectively collected neonatal TI data obtained from the National Emergency Airway Registry for Neonates (NEAR4NEOS), an international multicentre quality improvement registry. This study includes data from 13 academic NICUs.

\section{Data collection}

Using a standardised NEAR4NEOS data collection form, each centre collected data on patient, provider, practice and outcomes for each neonatal TI encounter. ${ }^{15}$ This data was recorded by a designated member of the care team immediately after the procedure and later verified for accuracy by the site's study team. Consistency of data captured was ensured by utilising NEAR4NEOS standardised operational definitions. Each participating NICU developed a site-specific compliance plan to ensure appropriate data capture of more than $90 \%$ of intubations, data verification and timely data entry into a secured, password-protected Research Electronic Data Capture (REDCap) system hosted by the data coordinating centre at Children's Hospital of Philadelphia. TI data from one site without consistent compliance reporting was excluded from the analysis.

Patient data included gestational age, postnatal age, birth weight, corrected weight on the day of TI, associated comorbidities and indication for intubation. Provider data included the profession and experience level of the intubating providers and members of the healthcare team present during the intubation. Practice data included intubation device used, dose and type of premedication and family presence.

\section{Inclusion and exclusion criteria}

All primary TIs in the NICU between October 2014 and December 2017 were included in the analysis. TIs performed outside the NICU, including in the delivery room, performed by non-NICU personnel or for endotracheal tube changes were excluded from the analysis.

\section{Exposure of interest}

The exposure of interest was family presence. The presence of family was defined as at least one family member present in the room during the procedure and was recorded on the NEAR4 NEOS form by a member of the intubation team as either 'yes' or 'no'.

\section{Definition of outcomes}

Specific outcomes of interest included the first attempt success (primary outcome), success within two intubation attempts, the occurrence of adverse TIAEs and a severe oxygen desaturation during the intubation. First attempt success was defined as successful intubation on the first attempt by the first provider. TIAEs were categorised as 'non-severe' or 'severe' using previously described operational definitions. ${ }^{15}$ Non-severe TIAEs included oesophageal intubation with immediate recognition, mainstem intubation, lip trauma, pain or agitation requiring additional sedation delaying intubation, epistaxis, emesis without aspiration, hypertension requiring therapy and dysrhythmia including bradycardia with heart rate $<60$ beats per minute or an arrhythmia requiring treatment. Severe TIAEs included direct airway injury, oesophageal intubation with delayed recognition, emesis with aspiration, laryngospasm, pneumothorax, gum or dental trauma, hypotension requiring intervention, malignant hyperthermia, need for cardiac compressions and cardiac arrest.

Oxygen desaturations were captured separately from adverse TIAEs. Pulse oximetry was used to identify two oxygen saturation $\left(\mathrm{SpO}_{2}\right)$ measurements for each intubation: the highest $\mathrm{SpO}_{2}$ measurement immediately before the first intubation attempt, and the lowest measured $\mathrm{SpO}_{2}$ during the intubation encounter. Severe oxygen desaturation was defined as $\geq 20 \%$ decrease in $\mathrm{SpO}_{2}$ from the highest level achieved immediately before the first intubation attempt. This was only reported for TIs in which a preintubation $\mathrm{SpO}_{2}$ level was recorded.

\section{Statistical analysis}

Descriptive statistics were used to present the demographic data as number and proportion for categorical variables and as median and IQR for non-parametric data. The relationships between the patient, provider and practice characteristics with family presence were analysed using univariate analyses with $\chi^{2}$ or Fisher's exact test for dichotomous variables and with KruskalWallis test for non-parametric variables. The independent effect of family presence on TI outcomes was assessed by generalised estimate equation multivariable logistic regression model while controlling for patient, provider, practice factors and clustering by site. Covariates were included in the multivariable model when there was an association with family presence at $p<0.1$ in the univariate analysis. Statistical analysis was performed using STATA V.14.0 (StataCorp).

\section{RESULTS}

A total of 2570 TIs out of 3437 TIs from 13 NICUs were reported (figure 1). Of those, $242(9.4 \%)$ had a family member present. Family presence during TI varied significantly between sites. The median percentage of intubations with family present per site was $3.6 \%$, with family presence ranging between $0 \%$ and $33 \%$ of intubation encounters per site, $\mathrm{p}<0.01$ (figure 2).

\section{Patient, provider and practice characteristics}

Patient characteristics are provided in table 1 . Family members were more likely to be present for older infants with chronic respiratory failure and less likely to be present for younger, smaller infants with apnoea and bradycardia or surfactant administration. Provider and practice characteristics are provided in table 2 . The most common primary airway providers in neonates with family present were neonatal nurse practitioners or physician assistants (43\%) followed by neonatal fellows (30\%). Fewer TIs were performed by residents when family was present (FP $10 \%$ vs no FP 18\%, $\mathrm{p}=0.041)$. Video laryngoscope was more 


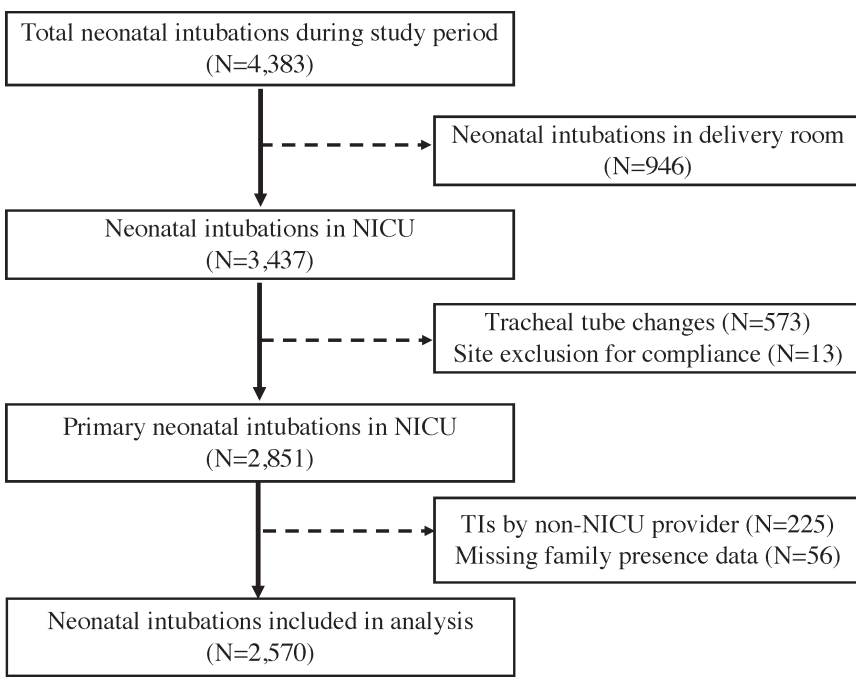

Figure 1 Study flow diagram for inclusion and exclusion. NICU, neonatal intensive care unit; TIs, tracheal intubations.

likely used and nasal intubation was less likely performed in TIs with family presence.

\section{Family presence and TI outcomes}

Among TIs with family presence versus without family presence, all TI outcomes except the success within two attempts were not different between two groups: the first attempt success rate was $55 \%$ vs $49 \%(\mathrm{p}=0.062)$, success within two attempts was $74 \%$ vs $66 \%(p=0.014)$, adverse TIAEs were $18 \%$ vs $20 \%(p=0.62)$ and severe oxygen desaturation was $49 \%$ vs $52 \%(\mathrm{p}=0.40)$, figure 3 and online supplemental table 1.

After adjusting for patient weight, patient condition for acute respiratory failure and chronic lung disease, indication for apnoea and bradycardia, upper airway obstruction, unstable haemodynamics, surfactant administration and unplanned extubation, the use of video laryngoscopy, nasal intubation, laryngoscopist training level and clustering by site, there were no independent associations between family presence and first attempt success (adjusted OR (aOR) $=1.14,95 \%$ CI 0.86 to 1.51$)$, success within two attempts (aOR $=1.24,95 \%$ CI 0.90 to 1.71$)$, adverse TIAEs $(\mathrm{aOR}=0.95,95 \% \mathrm{CI} 0.67$ to 1.37$)$ or severe oxygen desaturation $(\mathrm{aOR}=0.91,95 \% \mathrm{CI} 0.69$ to 1.20 ), tables 3 and 4 (online supplemental tables 2-4).

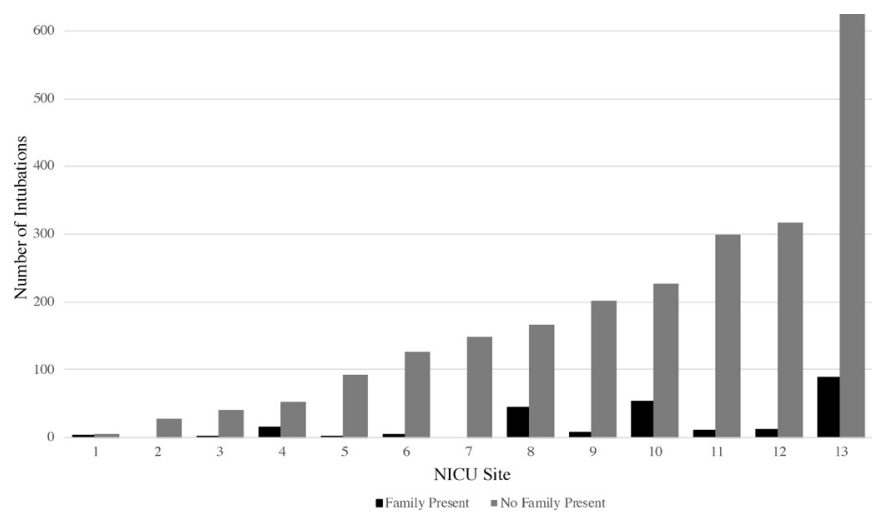

Figure 2 Institutional variation of family presence during intubations $(\mathrm{n}=2570)$. NICU, neonatal intensive care unit.
Table 1 Patient characteristics stratified by family presence

\begin{tabular}{|c|c|c|c|}
\hline Characteristics ( $N=2570)$ & $\begin{array}{l}\text { Family absent } \\
(n=2328)\end{array}$ & $\begin{array}{l}\text { Family present } \\
(n=242)\end{array}$ & $P$ value \\
\hline \multicolumn{4}{|l|}{ Patient characteristics } \\
\hline GA at birth (week, median (IQR)) & $28(25-34)$ & $30(25-37)$ & 0.009 \\
\hline Age (day, median (IQR)) & $10(1-45)$ & $22(2-70)$ & 0.0004 \\
\hline Weight at intubation ( $\mathrm{g}$, median (IQR)) & $1633(946-2900)$ & $2523(1202-3425)$ & 0.0001 \\
\hline History of difficult airway, $\mathrm{n}(\%)$ & $191(8)$ & $22(9)$ & 0.6 \\
\hline \multicolumn{4}{|l|}{ Comorbidity, n (\%) } \\
\hline Sepsis & $152(7)$ & $15(6)$ & 0.8 \\
\hline Congenital cardiac disease & $148(6)$ & $20(8)$ & 0.3 \\
\hline $\begin{array}{l}\text { Anatomic congenital anomaly requiring } \\
\text { surgery }\end{array}$ & $169(7)$ & $21(9)$ & 0.4 \\
\hline Airway or craniofacial anomaly & $123(5)$ & $16(7)$ & 0.4 \\
\hline Neurologic impairment & $166(7)$ & $20(8)$ & 0.5 \\
\hline Acute respiratory failure & $1414(61)$ & $125(52)$ & 0.006 \\
\hline Chronic respiratory failure & $535(23)$ & $72(30)$ & 0.02 \\
\hline Surgery/procedure for acquired disorder & $36(2)$ & $7(3)$ & 0.1 \\
\hline \multicolumn{4}{|l|}{ Initial intubation indication, $\mathrm{n}(\%)^{*} \dagger$} \\
\hline $\begin{array}{l}\text { Oxygen failure (eg, } \mathrm{PaO}_{2}<60 \mathrm{~mm} \mathrm{Hg} \\
\text { in Fio }{ }_{2}>0.6 \text { in the absence of cyanotic } \\
\text { heart disease }\end{array}$ & $706(30)$ & $75(31)$ & 0.8 \\
\hline $\begin{array}{l}\text { Ventilation failure (eg, Paco }>50 \mathrm{~mm} \\
\mathrm{Hg} \text { in the absence of chronic lung } \\
\text { disease) }\end{array}$ & $852(37)$ & $87(36)$ & 0.8 \\
\hline Frequent apnoea and bradycardia & $499(21)$ & $29(12)$ & 0.001 \\
\hline Upper airway obstruction & $101(4)$ & $24(10)$ & $<0.0001$ \\
\hline Procedure & $241(10)$ & $26(11)$ & 0.9 \\
\hline $\begin{array}{l}\text { Unstable haemodynamics (eg, shock, } \\
\text { CPR) }\end{array}$ & $52(2)$ & $12(5)$ & 0.02 \\
\hline Surfactant administration & $481(21)$ & $25(10)$ & $<0.0001$ \\
\hline $\begin{array}{l}\text { Reintubation after unplanned } \\
\text { extubation }\end{array}$ & $269(12)$ & $40(17)$ & 0.02 \\
\hline
\end{tabular}

\section{Resident participation and family presence}

The participation of a paediatric resident as a laryngoscopist was associated with less family presence (with resident participation: $10.3 \%$ vs without resident participation: $17.8 \%, \mathrm{p}=0.003$ ). This association remained significant after adjusting for factors

\begin{tabular}{|c|c|c|c|}
\hline $\begin{array}{l}\text { Provider and practice characteristics } \\
(\mathrm{N}=2570)\end{array}$ & $\begin{array}{l}\text { Family absent } \\
(\mathrm{n}=2328)\end{array}$ & $\begin{array}{l}\text { Family present } \\
(\mathrm{n}=242)\end{array}$ & $P$ value \\
\hline \multicolumn{4}{|l|}{ Primary airway provider $(\mathrm{n}(\%))^{*}$} \\
\hline Paediatric resident & $415(18)$ & $25(10)$ & \multirow[t]{5}{*}{0.041} \\
\hline Neonatology fellow & $742(32)$ & $73(30)$ & \\
\hline Neonatology attending & $173(7)$ & $23(10)$ & \\
\hline Nurse practitioner/physician assistant & $853(37)$ & $105(43)$ & \\
\hline Other (hospitalists, respiratory therapist) & $144(6)$ & $16(7)$ & \\
\hline \multicolumn{4}{|l|}{ Intubation device $(\mathrm{n}(\%)) \dagger$} \\
\hline Direct laryngoscope & $1824(78)$ & $168(69)$ & \multirow[t]{2}{*}{0.006} \\
\hline Video laryngoscope & $501(22)$ & $74(31)$ & \\
\hline \multicolumn{4}{|l|}{ Intubation approach (n (\%)) } \\
\hline Oral & $2147(92)$ & $237(98)$ & \multirow[t]{3}{*}{$<0.0001$} \\
\hline Nasal & $171(8)$ & $3(1)$ & \\
\hline Other & $10(0)$ & $2(1)$ & \\
\hline \multicolumn{4}{|l|}{ Premedication $(\mathrm{n}(\%)) \ddagger$} \\
\hline No sedation & $857(37)$ & $84(35)$ & \multirow[t]{3}{*}{0.85} \\
\hline Sedation only & $416(18)$ & $41(17)$ & \\
\hline Sedation and paralysis & $1046(45)$ & $116(48)$ & \\
\hline
\end{tabular}

*One encounter missing provider information.

tOne intubation utilised a non-laryngoscopy device.

¥Ten intubations utilised only a paralytic. 


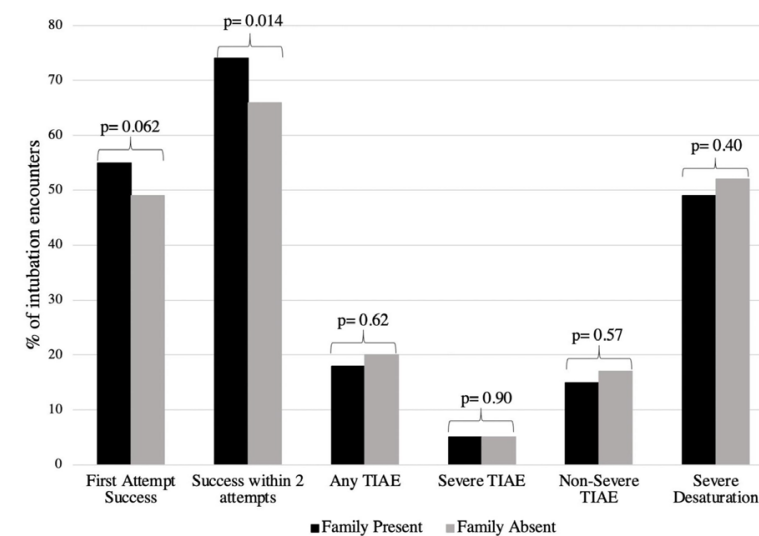

TIAEs: Adverse TI associated events Non-severe TIAEs: esophageal intubation with immediate recognition, dysshythmia, epistaxis, lip trauma, agitation, mainste intubation, emesis with no aspiration, hypertension
Severe TiAEs esophageal intubation with delayed recognition, direct airway injury, pneumothorax, gum or dental trauma
emesis with aspiration, hypotension, laryngospasm, malignant hyperthermia, cardiac compressions, or cardiac arrest Severe desaturation: $\geq 20 \%$ drop in oxygen saturation during intubation attemp

Figure 3 Univariate analysis of family presence during neonatal intubation with tracheal intubation outcomes.

associated with family presence identified in the analyses above (adjusted OR $(\mathrm{aOR})=0.57,95 \% \mathrm{CI}: 0.36$ to $0.88, \mathrm{p}=0.012$ ).

\section{DISCUSSION}

Using the NEAR4NEOS TI database, we described the current practice of family presence during neonatal TIs and associations of family presence with TI outcomes. Across the registry, family members were present in less than $10 \%$ of intubations. Intubations of infants with older gestational age at birth, larger weight at intubation and chronic respiratory failure had family presence during intubation more often. Fewer TIs were performed by residents when family was present. After adjusting for patient, practice, provider characteristics and clustering by site, there were no independent associations between family presence and success, adverse TIAEs or severe desaturation. To the authors' knowledge, this is the first study to report on family presence during neonatal TIs and to investigate the association of family presence on TI outcomes across the NICUs.

This study's first aim sought to describe the current practice of family presence during neonatal TIs across multiple NICUs. We found that across the 13 NICUs, family was present in $9 \%$ of intubations, which is lower than that previously reported in the PICU, where family was present during 19\% of intubations. ${ }^{14}$ Moreover, family presence in our NICUs was highly variable, ranging from $0 \%$ to $33 \%$ of intubations, which may be secondary to a variety of reasons including differing unit policies, unit culture or provider group comfort between the sites. The lower incidence of family presence, compared with the PICU, could be secondary to differences in these environments and hospital courses. We found that family presence was less during TIs in younger, smaller infants intubated for surfactant delivery, which may reflect separation in the immediate newborn

\begin{tabular}{|c|c|c|c|}
\hline Tracheal intubation outcomes & Adjusted OR & $95 \% \mathrm{Cl}$ & $P$ value \\
\hline First attempt success & 1.14 & 0.86 to 1.51 & 0.35 \\
\hline Success within two TI attempts & 1.24 & 0.90 to 1.17 & 0.18 \\
\hline Adverse $\mathrm{Tl}$ associated events & 0.95 & 0.67 to 1.37 & 0.8 \\
\hline Severe desaturation & 0.91 & 0.69 to 1.20 & 0.51 \\
\hline
\end{tabular}

$\mathrm{Tl}$, tracheal intubation.
Table 4 Generalised estimate equation model multivariable analysis for the association between family presence and first attempt success (primary outcome) adjusted for patient, provider and practice factors

\begin{tabular}{|c|c|c|c|}
\hline & OR & $95 \% \mathrm{Cl}$ & $P$ value \\
\hline Family member present & 1.14 & 0.86 to 1.51 & 0.352 \\
\hline \multicolumn{4}{|l|}{ Patient } \\
\hline Weight $\geq 1500 \mathrm{~g}$ & 1.41 & 1.17 to 1.70 & $<0.001$ \\
\hline \multicolumn{4}{|l|}{ Comorbidities } \\
\hline Acute respiratory failure & 1.11 & 0.89 to 1.40 & 0.358 \\
\hline Chronic respiratory failure & 0.81 & 0.63 to 1.04 & 0.096 \\
\hline \multicolumn{4}{|l|}{ Indication } \\
\hline Frequent apnoea and bradycardia & 0.84 & 0.67 to 1.04 & 0.105 \\
\hline Upper airway obstruction & 1.03 & 0.70 to 1.51 & 0.886 \\
\hline Unstable haemodynamics & 0.92 & 0.55 to 1.54 & 0.760 \\
\hline Surfactant administration & 0.85 & 0.68 to 1.10 & 0.189 \\
\hline Reintubation after unplanned extubation & 1.42 & 1.10 to 1.86 & 0.011 \\
\hline \multicolumn{4}{|l|}{ Provider } \\
\hline Neonatology attending & 1 (reference) & N/A & N/A \\
\hline Neonatology fellow & 0.67 & 0.47 to 0.96 & 0.029 \\
\hline Paediatric resident & 0.20 & 0.13 to 0.29 & $<0.001$ \\
\hline Nurse practitioner & 0.59 & 0.41 to 0.86 & 0.006 \\
\hline Physician assistant & 0.62 & 0.41 to 0.92 & 0.019 \\
\hline Hospitalist/RT/other & 0.53 & 0.34 to 0.82 & 0.005 \\
\hline \multicolumn{4}{|l|}{ Practice } \\
\hline $\begin{array}{l}\text { Device-video laryngoscopy } \\
\text { (vs direct laryngoscopy) }\end{array}$ & 1.46 & 1.19 to 1.80 & $<0.001$ \\
\hline Approach—nasal (vs oral) & 1.99 & 1.38 to 2.86 & $<0.001$ \\
\hline
\end{tabular}

period. Additionally, the average length of stay in the NICU for a premature infant ranges from weeks to months, whereas in the PICU length of stay is much shorter. ${ }^{16}$ Due to longer NICU stays and often unpredictable needs for intubation, family may not be physically present in the NICU at the time of intubation.

The variability of family presence between different NICUs roughly matches the variation in presence between individual PICU centres with reported rates of $0 \%-43 \% .{ }^{14}$ The variability in the rate of family presence during TIs supports the fact that family presence during invasive procedures is not a universally accepted practice. Other studies have cited several contributing factors such as clinician discipline, provider experience level, geographical region, hospital department, unit visitation restrictions, the invasiveness of the procedure, and lack of unit policies and clinical practice guidelines. ${ }^{9} 1317$ Our study showed that a family was less likely present during intubation when a paediatric resident participated as a laryngoscopist. Other studies also described that attending physicians and nurses are more willing to include family during invasive procedures than residents, as trainees may fear judgement of their skills by parents. ${ }^{18} 19$ Additionally, many clinicians support family presence during less invasive procedures such as venipuncture but are more reluctant to offer the option for families to stay at the bedside during more invasive procedures such as $\mathrm{TI}^{20}$ Furthermore, a lack of unit policies on family presence during invasive procedures such as TI may contribute to the practice variation. ${ }^{18}$

The second aim of the study was to examine the associations between family presence during neonatal TI and TI outcomes. After adjusting for potential confounders, family presence was not independently associated with any specified TI outcomes. Our observations are consistent with findings of other investigations using the National Emergency Airway Registry for Children (NEAR4KIDS), which also found no evidence that family presence significantly impacts TI patient outcomes in the 
PICU. ${ }^{14}$ However, we found an association between family presence and the training level of the primary airway provider. In our study, we found that TIs performed by paediatric residents were less likely to have family presence. This finding contrasts with that seen in the NEAR4KIDS study, where paediatric residents were more likely to be the initial airway clinician when family was present. This PICU finding was thought to be a confounding by the level of patient stability: the TIs in stable patients will likely have resident participation and family presence during the TI in the PICU. Additionally, unit policies may specify primary airway providers in certain scenarios. Further studies are needed to investigate how family presence impacts the educational environment at the bedside.

Our study results support that family members should be offered the opportunity to be present during neonatal intubations without fear of compromising the safety of the procedure or increasing the risk of adverse patient outcomes. Our results add to previous studies that have shown that family presence rarely interferes with the procedure being performed ${ }^{1821-23}$ nor does family presence adversely affect the skills or anxiety levels of the providers. ${ }^{11}{ }^{24-27}$ Our data supporting family presence during neonatal intubations is important since many family members not only desire to be present during procedures and resuscitations but their presence has notable positive benefits including decreasing both patient and family members' anxiety ${ }^{1328}$ and is beneficial during the grieving process if a poor outcome occurs during a resuscitation. ${ }^{29} 30$ The findings of our study can support the development of unit policies for family presence during intubations. Future studies could evaluate the perspectives of neonatal providers regarding family presence during neonatal TIs to better delineate barriers to implementing policies regarding family presence during procedures. Similarly, the family perspective regarding observing the neonatal TI needs to be evaluated to gain insight on their perceptions of the experience and how healthcare teams can optimise FCC, such as designating a staff member to support families during the procedure.

This study has several limitations. First, this was an observational study and there was no randomisation of family presence during TIs. Therefore, our data may be subject to selection bias for family presence by the clinicians based on patient-level risks or planned trainee participation in TI. It is likely that there were unmeasured confounders that affect both family presence and the TI safety outcomes. We attempted to account for the source of bias due to unbalanced patient characteristics using multivariable logistic regression, nevertheless we were not able to control for unmeasured confounders. A prospective randomised control trial or quasi-experimental study design would be needed for definitive answers. Second, our study included NICU intubation data from only 13 NICUs and the majority of participating NICUs were within academic institutions. Therefore, our finding may not be generalisable to all NICUs. Third, this analysis used intubation data, which was self-reported by the team at the time of intubation and therefore may be influenced by reporting bias. The NEAR4NEOS collaborative has implemented universal operational definitions and data coordinator education to minimise these reporting bias across the sites. We do not have information from each participating unit regarding the presence of a formal policy on family presence at the time of study. It is not certain whether more families were offered the opportunity to stay for the procedure and declined to stay or were never asked by the provider team. Similarly, we do not know the role that patient acuity played in whether family was invited or allowed to stay during an intubation.

\section{CONCLUSION}

Family presence occurs in less than $10 \%$ of TIs and the practice varies widely across NICUs participating in the NEAR4NEOS registry. Family presence was not associated with differences in first attempt success, success within two attempts, occurrence of adverse TIAEs or severe oxygen desaturation, even after adjusted for potential confounders and variation across sites. These results suggest that family presence during neonatal TI can be considered as part of an FCC model in the NICU without impacting overall safety and success of the procedure.

\section{Author affiliations}

${ }^{1}$ Pediatrics, Division of Neonatology, University of Nebraska Medical Center, Omaha, Nebraska, USA

${ }^{2}$ Pediatrics, Division of Neonatology, University of Washington School of Medicine, Seattle, Washington, USA

${ }^{3}$ Department of Pediatrics, Madigan Army Medical Center, Tacoma, Washington, USA ${ }^{4}$ Department of Pediatrics, Division of Neonatology, The Children's Hospital of Philadelphia, Philadelphia, Pennsylvania, USA

${ }^{5}$ Department of Pediatrics, Division of Neonatology, Penn State Health Milton S Hershey Medical Center, Hershey, Pennsylvania, USA

${ }^{6}$ Perinatal Institute, Department of Pediatrics, Cincinnati Children's Hospital Medical Center, Cincinnati, Ohio, USA

${ }^{7}$ Pediatrics, University of Cincinnati College of Medicine, Cincinnati, Ohio, USA

${ }^{8}$ Neonatology, Dartmouth-Hitchcock Medical Center, Lebanon, New Hampshire, USA

${ }^{9}$ Pediatrics, Universitatsklinikum Schleswig-Holstein, Kiel, Schleswig-Holstein,

Germany

${ }^{10}$ Department of Pediatrics, Yale School of Medicine, New Haven, Connecticut, USA

1 Pediatrics- Neonatology, Centre Hospitalier Universitaire Sainte-Justine, Montreal,

Québec, Canada

${ }^{12}$ Nursing and Respiratory Care, The Children's Hospital of Philadelphia, Philadelphia,

Pennsylvania, USA

${ }^{13}$ Pediatrics, Section of Neonatology, University of Colorado Denver School of

Medicine, Aurora, Colorado, USA

${ }^{14}$ Department of Neonatology, KK Women's and Children's Hospital, Singapore

${ }^{15}$ Pediatrics, WakeMed Health and Hospitals, Raleigh, North Carolina, USA

${ }^{16}$ Epidemiology and Biostatistics, University of Pennsylvania Perelman School of Medicine, Philadelphia, Pennsylvania, USA

${ }^{17}$ Pediatrics, Section of Neonatology, University of Calgary Cumming School of Medicine, Calgary, Alberta, Canada

${ }^{18}$ Anesthesiology and Critical Care Medicine, The Children's Hospital of Philadelphia, Philadelphia, Pennsylvania, USA

${ }^{19}$ Center for Simulation, Advanced Education, and Innovation, The Children's Hospital of Philadelphia, Philadelphia, Pennsylvania, USA

\section{Twitter Anne Ades @anmoad}

Acknowledgements The authors would like to thank the healthcare teams at participating NEAR4NEOS sites for their diligent completion of NEAR4NEOS data collection forms. They also like to thank Hayley Buffman at Children's Hospital of Philadelphia as a coordinator for the NEAR4NEOS collaborative. Dr Brei's affiliation is updated to reflect change in employment.

Collaborators The NEAR4NEOS Investigators.

Funding TS is supported by NICHD 1R21HD091687 and 1R21HD089151. RU is supported by AHRQ 1R18HS027259-01. AN and NN are supported by NICHD 1R21HD089151, AHRQ R18HS02264 and R18HS024511. EEF is supported by an NICHD Career Development Award K23HD084727.

Competing interests NN has research/consulting relationships with Dräger Medical, Smiths Medical, Aerogen, Philips/Respironics and VERO-Biotech.

\section{Patient consent for publication Not required.}

Ethics approval The institutional review board at each participating NEAR4NEOS site either approved the study or granted a waiver of informed parental consent for the use of patient data as a quality improvement activity.

Provenance and peer review Not commissioned; externally peer reviewed.

Data availability statement All data relevant to the study are included in the article or uploaded as supplementary information.

Supplemental material This content has been supplied by the author(s). It has not been vetted by BMJ Publishing Group Limited (BMJ) and may not have been peer-reviewed. Any opinions or recommendations discussed are solely those of the author(s) and are not endorsed by BMJ. BMJ disclaims all liability and responsibility arising from any reliance placed on the content. Where the content includes any translated material, BMJ does not warrant the accuracy and reliability 
of the translations (including but not limited to local regulations, clinical guidelines, terminology, drug names and drug dosages), and is not responsible for any error and/or omissions arising from translation and adaptation or otherwise.

Open access This is an open access article distributed in accordance with the Creative Commons Attribution Non Commercial (CC BY-NC 4.0) license, which permits others to distribute, remix, adapt, build upon this work non-commercially, and license their derivative works on different terms, provided the original work is properly cited, appropriate credit is given, any changes made indicated, and the use is non-commercial. See: http://creativecommons.org/licenses/by-nc/4.0/.

ORCID iDs

Brianna K Brei http://orcid.org/0000-0003-0481-3597

Megan M Gray http://orcid.org/0000-0002-3272-9432

Elizabeth E Foglia http://orcid.org/0000-0002-9925-5219

Ahmed Moussa http://orcid.org/0000-0002-2556-6970

\section{REFERENCES}

1 COMMITTEE ON HOSPITAL CARE and INSTITUTE FOR PATIENT- AND FAMILYCENTERED CARE. Patient- and family-centered care and the pediatrician's role. Pediatrics 2012;129:394-404

2 Franck LS, O'Brien K, O'Brien K. The evolution of family-centered care: from supporting parent-delivered interventions to a model of family integrated care. Birth Defects Res 2019;111:1044-59

3 Abdel-Latif ME, Boswell D, Broom M, et al. Parental presence on neonatal intensive care unit clinical bedside rounds: randomised trial and focus group discussion. Arch Dis Child Fetal Neonatal Ed 2015;100:F203-9.

4 Cooper LG, Gooding JS, Gallagher J, et al. Impact of a family-centered care initiative on NICU care, staff and families. J Perinatol 2007;27:S32-7.

5 Ramezani T, Hadian Shirazi Z, Sabet Sarvestani R, et al. Family-centered care in neonatal intensive care unit: a concept analysis. Int $J$ Community Based Nurs Midwifery 2014;2:268-78.

6 Davidson JE, Aslakson RA, Long AC, et al. Guidelines for Family-Centered care in the neonatal, pediatric, and adult ICU. Crit Care Med 2017;45:103-28.

7 Gooding JS, Cooper LG, Blaine Al, et al. Family support and family-centered care in the neonatal intensive care unit: origins, advances, impact. Semin Perinatol 2011:35:20-8.

8 Kleinman ME, Chameides L, Schexnayder SM, et al. Part 14: pediatric advanced life support: 2010 American heart association guidelines for cardiopulmonary resuscitation and emergency cardiovascular care. Circulation 2010;122:S876-908.

9 Dingeman RS, Mitchell EA, Meyer EC, et al. Parent presence during complex invasive procedures and cardiopulmonary resuscitation: a systematic review of the literature. Pediatrics 2007;120:842-54.

10 Engel KG, Barnosky AR, Berry-Bovia M, et al. Provider experience and attitudes toward family presence during resuscitation procedures. J Palliat Med 2007;10:1007-9.

11 Curley MAQ, Meyer EC, Scoppettuolo LA, et al. Parent presence during invasive procedures and resuscitation. Am J Respir Crit Care Med 2012;186:1133-9.
12 Nishisaki A, Diekema DS. Mind the gap and narrowing it: family presence during pediatric resuscitation and invasive procedures. Resuscitation 2011;82:655-6.

13 Beesley SJ, Hopkins RO, Francis L, et al. Let them in: family presence during intensive care unit procedures. Ann Am Thorac Soc 2016;13:1155-9.

14 Sanders RC, Nett ST, Davis KF, et al. Family presence during pediatric tracheal Intubations. JAMA Pediatr 2016;170:e154627.

15 Foglia EE, Ades A, Sawyer T, et al. Neonatal intubation practice and outcomes: an international registry study. Pediatrics 2019;143:1-3. doi:10.1542/peds.20180902

16 Pollack MM, Holubkov R, Reeder R, et al. PICU length of stay: factors associated with bed utilization and development of a benchmarking model. Pediatr Crit Care Med 2018;19:196-203.

17 Ditzel A. Parent Presence During Invasive Procedures: The Implementation of a Clinical Practice Guideline and Educational Initiative [dissertation on the Internet]. Mansfield, CT: University of Connecticut, 2016. https://opencommons.uconn.edu/dissertations/ 1254

18 Mangurten J, Scott SH, Guzzetta CE, et al. Effects of family presence during resuscitation and invasive procedures in a pediatric emergency department. J Emerg Nurs 2006;32:225-33.

19 Bensouda B, Mandel R, Mejri A, et al. Effect of an audience on trainee stress and performance during simulated neonatal intubation: a randomized crossover trial. $B M C$ Med Educ 2018:18:230.

20 Waseem M, Ryan M. Parental presence during invasive procedures in children: what is the physician's perspective? South Med J 2003;96:884-7.

21 Sacchetti A, Paston C, Carraccio C. Family members do not disrupt care when present during invasive procedures. Acad Emerg Med 2005;12:477-9.

22 Dudley NC, Hansen KW, Furnival RA, et al. The effect of family presence on the efficiency of pediatric trauma resuscitations. Ann Emerg Med 2009;53:777-84.

$23 \mathrm{O}^{\prime}$ Connell KJ, Farah MM, Spandorfer P, et al. Family presence during pediatric trauma team activation: an assessment of a structured program. Pediatrics 2007;120:e565-74.

24 Bauchner H, Vinci R, Bak S, et al. Parents and procedures: a randomized controlled trial. Pediatrics 1996;98:861-7.

25 Rittenmeyer L, Huffman D. How families and health care practitioners experience family presence during resuscitation and invasive procedures. JBI Libr Syst Rev 2012;10:1785-882.

26 Wolfram RW, Turner ED. Effects of parental presence during children's venipuncture. Acad Emerg Med 1996;3:58-64.

27 Boyd R, White S. Does witnessed cardiopulmonary resuscitation alter perceived stress in accident and emergency staff? Eur J Emerg Med 2000;7:51-3.

28 Powers KS, Rubenstein JS. Family presence during invasive procedures in the pediatric intensive care unit: a prospective study. Arch Pediatr Adolesc Med 1999;153:955-8.

29 Tinsley C, Hill JB, Shah J, et al. Experience of families during cardiopulmonary resuscitation in a pediatric intensive care unit. Pediatrics 2008;122:e799-804.

30 Robinson SM, Mackenzie-Ross S, Campbell Hewson GL, et al. Psychological effect of witnessed resuscitation on bereaved relatives. Lancet 1998;352:614-7. 